\title{
Determination of surface crack orientation based on thin-skin regime using triple-coil drive-pickup eddy-current sensor
}

\author{
Mingyang Lu*, Xiaobai Meng, Ruochen Huang, Liming Chen, Zezhi Tang, Junshi Li, Anthony Peyton, Wuliang Yin*
}

\begin{abstract}
Electromagnetic sensors have been used for inspecting small surface defects of metals. Based on the eddycurrent thin-skin regime, a revised algorithm is proposed for a triple-coil drive-pickup eddy-current sensor scanning over long surface crack slots $(10 \mathrm{~mm})$ with different rotary angles. The method is validated by the voltage measurement of the designed EC sensor scanning over a benchmark (ferromagnetic) steel with surface defects of different depths and rotary angles. With an additional sensing coil for the designed $\mathrm{EC}$ sensor, the defect angle (or orientation) can be measured without spatially and coaxially rotating the excitation coil. By referring to the voltage change (due to the defect) diagram (voltage sum versus voltage different) of two sensing pairs, the rotary angle of the surface crack is retrieved with a maximum residual deviation of $3.5 \%$.
\end{abstract}

Index Terms - Eddy current sensor; defect orientation; angled crack, thin-skin regime; non-destructive testing.

\section{INTRODUCTION}

$\mathrm{E}$ DDY current (EC) sensors are used for the monitoring of structural integrity [1-9] and measurement of material properties [10-17]. For the inspecting of defects, ultrasonic transducers are efficient in the identification of defect clusters [18]. Moreover, magnetic flux leakage (MFL) sensors have a higher probability of the inspecting of near-surface (or breaking-points) defects [19]. Compared to ultrasonic and MFL techniques, the EC testing commonly applies to the measurement of small surface defects like head checks and gauge corner cracking, particularly for the high-speed inspection (especially above $15 \mathrm{~km} / \mathrm{h}$ ) applied to inspect the rolling contact fatigue (RCF) of the rail [18,20].

Both analytical [21-23] and numerical methods [24,25] have been proposed for the interaction analysis between EC sensors and surface crack slots on metals. For the analytical technique, combining the Harfield-Bowler eddy-current thin-skin model [26] with a two-port system of surface-integral formulas proposed by Auld [27], Burke and Ditchburn have proposed the analytical model of mutual impedance change due to an ideal surface crack [28]. Moreover, Theodoulidis has proposed the revised analytical model for the tilted single-coil sensor above the surface slot [29]. For the numerical method, both Finite-

This work was supported by [UK Engineering and Physical Sciences Research Council (EPSRC)] [grant number: EP/P027237/1] [title: Real-time Inline Microstructural Engineering (RIME)].

M. Lu (MIEEE), R. Huang, L. Chen, Z. Tang, J. Li, A. Peyton, and W. Yin (SMIEEE) are with the School of Electrical and Electronic Engineering, element (FE) models [30] and boundary element (BE) models [31] have been used for the impedance analysis of EC sensors inspecting the surface crack. Proposed techniques are based on different models and strategies, including the alternating current field measurement (ACFM) [32,33], rotating field inspection [34,35], multi-frequency EC sensor [36], scanning EC sensor [37], and perturbed matrix method [38].

For measuring the orientation of surface defect, Theodoulidis, Panas, and Kriezis have proposed an elliptical excitation, which can preciously measure the crack orientation. However, the method needs to spatially and coaxially (with respect to the crack) rotate the excitation coil [39]. Besides, the method is based on the approximation that the thickness of the plate is relatively small (compared to the electromagnetic (EM) skin depth). Moreover, the rotational GMR-EC magnetometer [40] and SQUID probe [41] have been used to detect the orientation of surface defects. Hamia, Cordier, and Dolabdjian have proposed a 3D FE based numerical model to simulate and predict the corresponding signal of an Improved Giant Magneto-Resistance Magnetometer (IGMRM) [18]. The proposed method has an improved detection sensitivity but only applies to the pseudo-rotating magnetic field generated by the excitation inducer.

In this paper, instead of using the numerical method, a revised analytical algorithm based on the eddy-current thin-skin regime is proposed for the triple-coil driver-pickup EC sensor scanning over surface slots of steels with different angles. Compared to the single (or co-axial) coil setup, the driverpickup has an extended frequency range, higher gain (and spatial resolution) [42], and less affected by the thermal drift [43]. Moreover, with an additional sensing coil, the designed sensor is able to detect the crack angle without spatially rotating the driver-pickup orientation. By using the voltage measurement apparatus with a controlled scanning stage, experiments have been produced on the triple-coil sensor scanning over a benchmark (carbon steel) with machined surface slots of different depths and rotating angles (using a rotary mount underneath the sample). The crack angle is retrieved by referring to the normalised voltage diagram (voltage sum versus voltage difference).

University of Manchester, Sackville Street Building, Manchester, M13 9PL, UK (mingyang.lu@manchester.ac.uk; wuliang.yin@manchester.ac.uk)

*Corresponding author: M. Lu, W. Yin.

$\mathrm{X}$. Meng is with the Faculty of Art, Science and Technology, University of Northampton, Northampton, NN1 5PH, UK 


\section{ANALYTICAL MODEL - EDDY CURRENT THIN-SKIN REGIME}

A. Original formulas of thin-skin regime - mutual-impedance of $T$-R coil scanning vertically over long surface crack

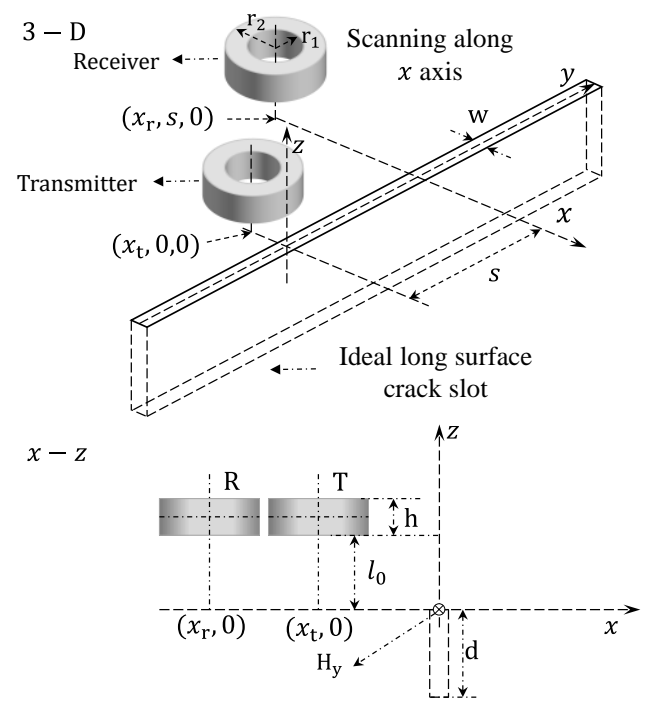

Fig. 1 Circular drive-pickup coils scanning vertically over long surface crack

The electromagnetic skin depth, $\delta$ can be computed by the following equation.

$$
\delta=\sqrt{\frac{1}{\pi \sigma \mu_{\mathrm{r}} \mu_{0} \mathrm{f}}}
$$

where $\sigma$ and $\mu_{\mathrm{r}}$ are the electrical conductivity and relative magnetic permeability of the test piece. $\mu_{0}$ is the vacuum magnetic permeability (of free space). $\mathrm{f}$ is the working frequency of the excitation current.

Fig. 1 shows the circular drive-pickup coil windings scanning vertically (along $x$ axis) over a long ideal surface slot of a conductive half-space. The analytical mutual impedance change caused by the surface slot is reported in [28], which is based on the eddy-current thin-skin regime proposed by Harfield and Bowler [26]. That is, for the case that the crack length and depth are over 3 to 4 times of the eddy-current skin depth (equation 1), the impedance change due to the surface slot can be well approximated by the following expression.

$$
\Delta \mathrm{Z}_{\mathrm{c}}=\mu_{0} \mathrm{f} \int_{-\infty}^{\infty} \frac{g(\mathrm{w})}{1+\frac{2 v \widetilde{U} \tanh (v \mathrm{~d})}{\mathrm{jk}}} \frac{\widetilde{H}_{y \mathrm{t}}(-v) \widetilde{H}_{y \mathrm{r}}(v)}{v^{2}} \mathrm{~d} v
$$

In (2), functions $g(\mathrm{w}), \widetilde{\mathrm{U}}$, and $\mathrm{k}$ are defined in the appendix. $\mathrm{d}$ and $\mathrm{w}$ are the depth and width of the surface slot, respectively. $\widetilde{H}_{y \mathrm{t}}$ and $\widetilde{H}_{y \mathrm{r}}$ are the Fourier transform of the magnetic scalar potential (from the transmitter or driver coil winding and receiver or pickup coil winding) along $y$ axis at $z=0$ for the test piece without defect. Assume $u$ and $v$ are the parameters for the 2-D Fourier transformation of the $x-y$ plane in the Cartesian coordinate system, $\widetilde{H}_{y \mathrm{t}}(v)$ and $\widetilde{H}_{y \mathrm{r}}(v)$ are defined as

$$
\begin{gathered}
\widetilde{H}_{y \mathrm{t}}(v)=v \int_{-\infty}^{\infty} \frac{\tilde{h}(u, v) \mathrm{e}^{\mathrm{j} u x_{\mathrm{t}}} \alpha_{1}}{\alpha\left(\mu_{\mathrm{r}} \alpha+\alpha_{1}\right)} \mathrm{d} u \\
\widetilde{H}_{y \mathrm{r}}(v)=v \int_{-\infty}^{\infty} \frac{\tilde{h}(u, v) \mathrm{e}^{\mathrm{j}\left(u x_{\mathrm{r}}+v s\right)} \alpha_{1}}{\alpha\left(\mu_{\mathrm{r}} \alpha+\alpha_{1}\right)} \mathrm{d} u
\end{gathered}
$$

where $x_{\mathrm{t}}$ and $x_{\mathrm{r}}$ are the displacements between coils and the crack slot along the scanning direction $(x-$ axis, which is vertical to the crack orientation in Fig. 1). $s$ is the fixed distance between the transmitter and receiver along $y-$ axis. $\alpha$ and $\alpha_{1}$ are related to the wavenumber of the EM plane wave of Transverse electric (TE) mode [17] in the free space and test piece, respectively.

$$
\begin{gathered}
\alpha=\sqrt{u^{2}+v^{2}} \\
\alpha_{1}=\sqrt{\alpha^{2}+\mathrm{j} 2 \pi \sigma \mu_{\mathrm{r}} \mu_{0} \mathrm{f}}
\end{gathered}
$$

$\tilde{h}(u, v) \mathrm{e}^{\mathrm{j} u x_{\mathrm{t}}}$ in (3) and $\tilde{h}(u, v) \mathrm{e}^{\mathrm{j}\left(u x_{\mathrm{r}}+v s\right)}$ in (4) are the Fourier transform of the free-space magnetic scalar potential generated by the driving transmitter and pick-up receiver respectively, with $\tilde{h}(u, v)$ defined as the following expression.

$$
\tilde{h}(u, v)=-\frac{\mathrm{jN}}{\mathrm{h}\left(\mathrm{r}_{2}-\mathrm{r}_{1}\right)} \frac{\mathrm{M}}{\alpha^{3}} \mathrm{e}^{-\alpha l_{0}} \sinh \left(\frac{\alpha \mathrm{h}}{2}\right)
$$

In (7), $r_{1}$ and $r_{2}$ are the inner and outer radius of the coil windings respectively; $\mathrm{N}$ and $\mathrm{h}$ are the number of turns and height of the coil windings respectively; $l_{0}$ is the (vertical) liftoff distance between the coil windings and test piece. $M$ denotes the integral defined in (8).

$$
M=\int_{j \alpha r_{1}}^{j \alpha r_{2}} \tau I_{1}(\tau) d \tau
$$

$\mathrm{I}_{1}$ denotes the first-order modified Bessel term of the first kind. The calculation of $\mathrm{M}$ can be accelerated by using the Struve functions, as shown in (9).

$$
\begin{aligned}
M= & \frac{j \pi \alpha}{2}\left\{r_{1}\left[I_{0}\left(j \alpha r_{1}\right) \mathbf{L}_{1}\left(j \alpha r_{1}\right)-I_{1}\left(j \alpha r_{1}\right) \mathbf{L}_{0}\left(j \alpha r_{1}\right)\right]\right. \\
& \left.-r_{2}\left[I_{0}\left(j \alpha r_{2}\right) \mathbf{L}_{1}\left(j \alpha r_{2}\right)-I_{1}\left(j \alpha r_{2}\right) \mathbf{L}_{0}\left(j \alpha r_{2}\right)\right]\right\}
\end{aligned}
$$

$\mathrm{I}_{n}$ and $\mathbf{L}_{n}$ are the first-kind modified Bessel and Struve functions with order $n$.

Moreover, the impedance for the driver-pickup EC sensor above the half-space without defect is

$$
\mathrm{Z}_{0}=\mathrm{j} 4 \pi \mu_{0} \text { If } \int_{-\infty}^{\infty} \int_{-\infty}^{\infty} \frac{\tilde{h}(-u,-v) \tilde{h}(u, v)\left(\mu_{\mathrm{r}} \alpha-\alpha_{1}\right) \mathrm{e}^{\mathrm{j} v s^{\prime}}}{\alpha\left(\mu_{\mathrm{r}} \alpha+\alpha_{1}\right)} \mathrm{d} u \mathrm{~d} v
$$

where $s^{\prime}$ is the distance between the transmitter and receiver. In Fig. $1, s^{\prime}$ is defined as

$$
\mathrm{s}^{\prime}=\sqrt{s^{2}+\left(x_{\mathrm{t}}-x_{\mathrm{r}}\right)^{2}}
$$

B. Revised algorithms - Mutual impedance for triple-coil T-R sensor scanning over long surface crack with different angles

Considering the blind scanning in the practical testing (where the orientation of the surface crack is an unknown factor), the EC sensor scans over the surface slot with an angle $\varphi$. For a certain displacement $x_{0}$ of the EC sensor with a single transmitter-receiver (T-R) sensing pair, it needs to spatially rotate the orientation of the T-R sensor pair for the aim of retrieving the crack angle $(\varphi)$ information. Therefore, it is assumed that a reference signal from an additional sensing pair could avoid the spatial rotating procedure.

As shown in Fig. 2, the EC sensor is designed as three identical coil windings, which is arranged in a line with the same spacing of $s$. Considering the balance of the background signal on two receiving (or sensing) coils $\left(\mathrm{R}_{1}\right.$ and $\mathrm{R}_{2}$ ) in the free space, the driving transmitter is placed between two pick-up 


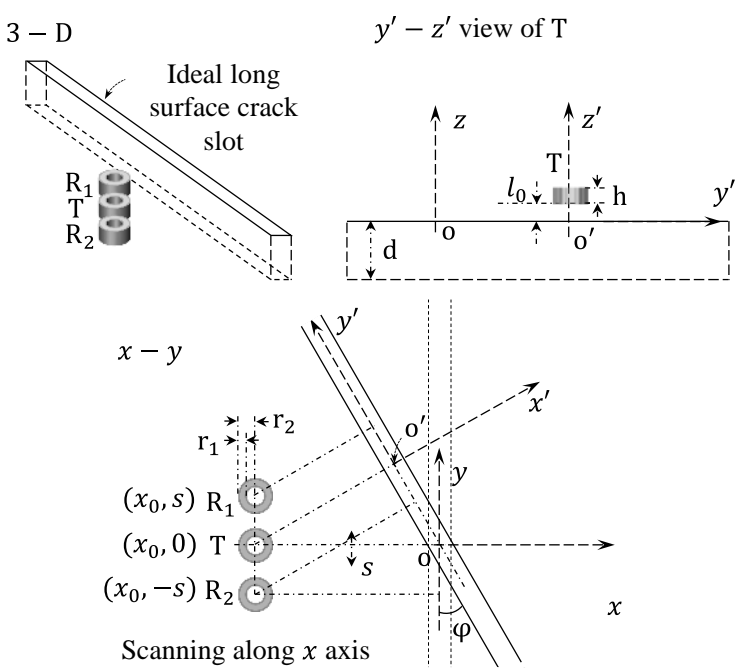

Fig. 2 Triple-coil drive-pickup sensor scanning over long surface crack with an angle of $\varphi$

receivers. The EC sensor scans along ( $x$ - axis) the vertical direction of the EC sensor orientation $\left(R_{1}-R_{2}\right)$. Assume the coordinate of $\mathrm{T}, \mathrm{R}_{1}$, and $\mathrm{R}_{2}$ coils (i.e. the centre for the bottom surface of the coil windings) are $\left(x_{0}, 0, l_{0}\right),\left(x_{0}, s, l_{0}\right)$, and $\left(x_{0},-s, l_{0}\right)$ respectively. When the surface slot rotates from vertical (along $y$ - axis) to an angle $(\varphi)$, the Cartesian coordinate system transfers from the $x-\mathrm{y}-z$ (originates at o ) system to the $x^{\prime}-\mathrm{y}^{\prime}-z^{\prime}$ (originates at $\mathrm{o}^{\prime}$ ) system. Consequently, the coordinate of $\mathrm{T}, \mathrm{R}_{1}$, and $\mathrm{R}_{2}$ coils in the $x^{\prime}-$ $\mathrm{y}^{\prime}-z^{\prime} \quad$ system becomes $\left(x_{0} \cos \varphi, 0, l_{0}\right), \quad\left(x_{0} \cos \varphi+\right.$ $\left.s \sin \varphi, s \cos \varphi, l_{0}\right), \quad$ and $\quad\left(x_{0} \cos \varphi-s \sin \varphi,-s \cos \varphi, l_{0}\right)$ respectively. Therefore, the free-space magnetic scalar potential generated by $\mathrm{T}, \mathrm{R}_{1}$, and $\mathrm{R}_{2}$ coils becomes

$$
\begin{gathered}
\tilde{h}(u, v) \mathrm{e}^{\mathrm{j} u x_{0} \cos \varphi} \\
\tilde{h}(u, v) \mathrm{e}^{\mathrm{j}\left(u\left(x_{0} \cos \varphi+s \sin \varphi\right)+v s \cos \varphi\right)} \\
\tilde{h}(u, v) \mathrm{e}^{\mathrm{j}\left(u\left(x_{0} \cos \varphi-s \sin \varphi\right)-v s \cos \varphi\right)}
\end{gathered}
$$

Thus, the Fourier transform of the magnetic scalar potential along $y$-axis at $z=0$ (for the test piece without defect) generated by $T, R_{1}$, and $R_{2}$ coils are expressed as the following equations.

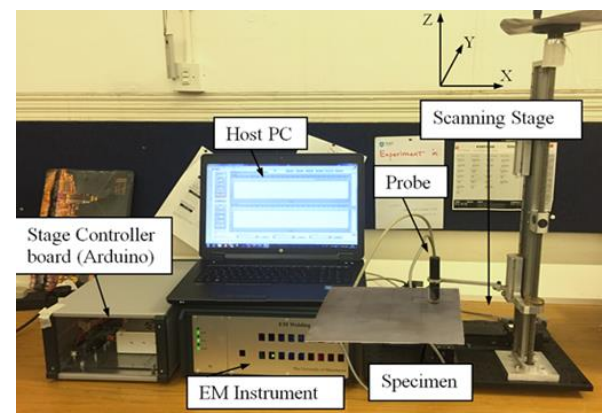

(a)

Machined surface slots with different depths

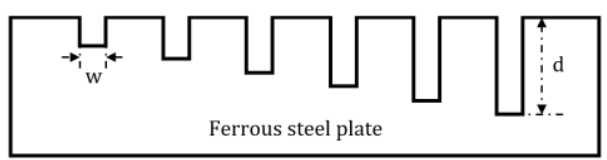

(b)

$$
\begin{aligned}
& \quad \widetilde{H}_{y \mathrm{t}}\left(v, x_{0}\right)=v \int_{-\infty}^{\infty} \frac{\tilde{h}(u, v) \mathrm{e}^{\mathrm{j} u x_{0} \cos \varphi} \alpha_{1}}{\alpha\left(\mu_{\mathrm{r}} \alpha+\alpha_{1}\right)} \mathrm{d} u \\
& \widetilde{H}_{y \mathrm{r} 1}\left(v, x_{0}\right) \\
& =v \int_{-\infty}^{\infty} \frac{\tilde{h}(u, v) \mathrm{e}^{\mathrm{j}\left(u\left(x_{0} \cos \varphi+s \sin \varphi\right)+v \cos \varphi\right)} \alpha_{1}}{\alpha\left(\mu_{\mathrm{r}} \alpha+\alpha_{1}\right)} \mathrm{d} u \\
& \widetilde{H}_{y \mathrm{r} 2}\left(v, x_{0}\right) \\
& =v \int_{-\infty}^{\infty} \frac{\tilde{h}(u, v) \mathrm{e}^{\mathrm{j}\left(u\left(x_{0} \cos \varphi-s \sin \varphi\right)-v \cos \varphi\right)} \alpha_{1}}{\alpha\left(\mu_{\mathrm{r}} \alpha+\alpha_{1}\right)} \mathrm{d} u
\end{aligned}
$$

Therefore, the impedance changes due to the crack from $\mathrm{T}-$ $\mathrm{R}_{1}$ and $\mathrm{T}-\mathrm{R}_{2}$ sensing pairs become

$$
\begin{aligned}
& \Delta \mathrm{V}_{\mathrm{t}-\mathrm{r} 11}\left(x_{0}\right) \\
& =\mu_{0} \text { If } \int_{-\infty}^{\infty} \frac{g(\mathrm{w})}{1+\frac{2 v \widetilde{\mathrm{U}} \tanh (v \mathrm{~d})}{\mathrm{jk}}} \frac{\widetilde{H}_{y \mathrm{t}}\left(-v, x_{0}\right) \widetilde{H}_{y \mathrm{r} 1}\left(v, x_{0}\right)}{v^{2}} \mathrm{~d} v \\
& \Delta \mathrm{V}_{\mathrm{t}-\mathrm{r} 2}\left(x_{0}\right) \\
& =\mu_{0} \text { If } \int_{-\infty}^{\infty} \frac{g(\mathrm{w})}{1+\frac{2 v \widetilde{\mathrm{U}} \tanh (v \mathrm{~d})}{\mathrm{jk}}} \frac{\widetilde{H}_{y \mathrm{t}}\left(-v, x_{0}\right) \widetilde{H}_{y \mathrm{r} 2}\left(v, x_{0}\right)}{v^{2}} \mathrm{~d} v
\end{aligned}
$$

In the practical measurement, discrepancies may occur between the measurement and calculated voltage. Therefore, voltage change in (18) or (19) is generally normalised by the non-defect absolute voltage (for the EC sensor above the test piece without defect, or the non-defect region), which can be expressed as

$$
\mathrm{V}_{0}=\mid \mathrm{j} 4 \pi \mu_{0} \text { If } \int_{-\infty}^{\infty} \int_{-\infty}^{\infty} \frac{\tilde{h}(-u,-v) \tilde{h}(u, v)\left(\mu_{\mathrm{r}} \alpha-\alpha_{1}\right) \mathrm{e}^{\mathrm{j} v \mathrm{~s}}}{\alpha\left(\mu_{\mathrm{r}} \alpha+\alpha_{1}\right)} \mathrm{d} u \mathrm{~d} v \mid
$$

\section{EXPERIMENT}

In Fig. 3, experiments have been carried out on the voltage measurement of the triple-coil probe scanning over surface slots with different rotary angles. As shown in Fig. 3 (a), the specimen is placed on a rotatory mount with an angle increment of 5 degrees. The voltage is measured by the custom apparatus - EM instrument fabricated by the SISP group at EEE, University of Manchester [44,45]. Moreover, the EC probe is controlled by a scanning stage with a custom board. The

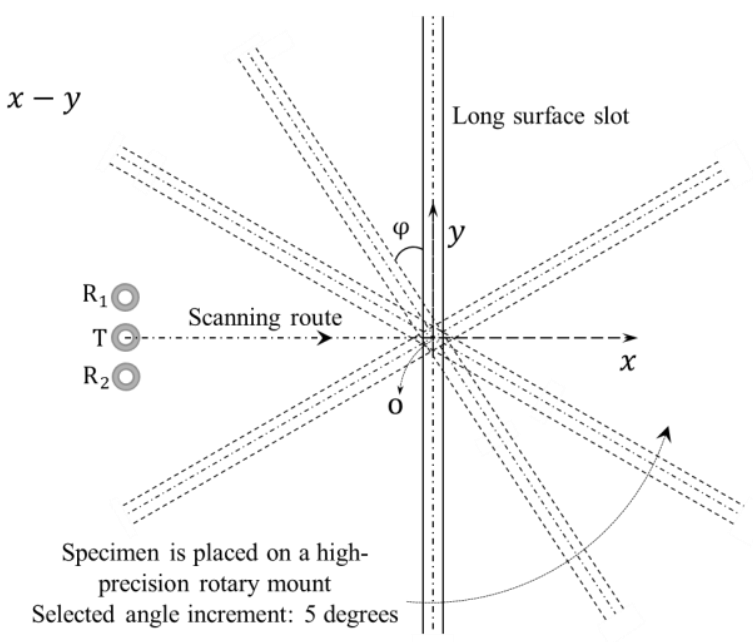

(c)

Fig. 3 Measurement setup (a) eddy-current scanning apparatus (b) Ferrous steel with ideally machined long surface slots of different depths (c) Scanning strategy - Triple-coil drive-pickup sensor scanning over long surface crack with different angles 
scanning step of the EC sensor is set at $0.25 \mathrm{~mm}$.

As listed in Table 1, to achieve a relatively high scanning resolution, the coils are wound with a small mean radius of 1 $\mathrm{mm}$ (which is much smaller than the crack length). In Table 2, to further test the effect of different depths on the crack orientation retrieval, the test piece (carbon steel) is machined with ideal surface slots of different depths (Fig. 3 b). To ensure that the EC thin-skin regime is valid for surface slots of different depths (where the length and depth of surface crack are 3 to 4 times of the skin depth calculated in 1), the working frequency of the excitation current is $40 \mathrm{kHz}$. The skin depth is $0.12 \mathrm{~mm}$ for the test piece (benchmark sample) under $40 \mathrm{kHz}$.

TABLE I

PARAMETERS OF THE TRIPLE-COIL DRIVE-PICKUP EDDY-CURRENT SENSOR AND MEASUREMENT SETUP

\begin{tabular}{cc}
\hline \hline Parameter of coils $\left(\mathrm{T}, \mathrm{R}_{1}, \mathrm{R}_{2}\right)$ & \\
\hline Inner radius $\mathrm{r}_{1}(\mathrm{~mm})$ & 0.75 \\
Outer radius $\mathrm{r}_{2}(\mathrm{~mm})$ & 1.25 \\
Number of turns N & 300 \\
Coil spacing $\mathrm{s}(\mathrm{mm})$ & 2.0 \\
Coil height $\mathrm{h}(\mathrm{mm})$ & 3.0 \\
Lift-off $l_{0}(\mathrm{~mm})$ & 2.0 \\
Working frequency $\mathrm{f}(\mathrm{kHz})$ & 40
\end{tabular}

Displacement along scanning $-5.0: 0.25: 5.0$

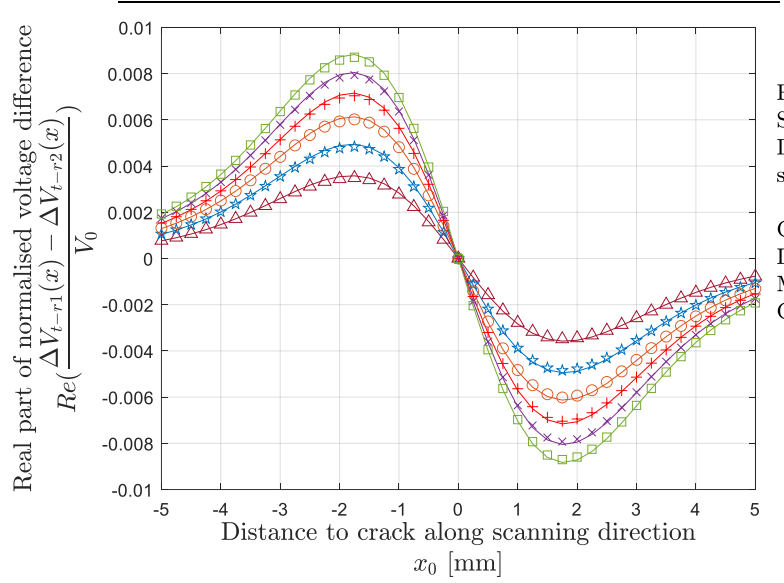

(a)

Frequency, $\mathrm{f}=40 \mathrm{kHz}$ Skin depth, $\delta=0.12 \mathrm{~mm}$ Distance to crack along scanning direction, $x_{0}$

\section{Crack depth, d} Lines - analytical result Markers - experimental result Crack angle, $\varphi=45$ [degree]

\begin{tabular}{|cl|}
\hline$\triangle$ & $\mathrm{d}=0.4 \mathrm{~mm}$ \\
मे & $\mathrm{d}=0.6 \mathrm{~mm}$ \\
0 & $\mathrm{~d}=0.8 \mathrm{~mm}$ \\
+ & $\mathrm{d}=1 \mathrm{~mm}$ \\
$\times$ & $\mathrm{d}=1.2 \mathrm{~mm}$ \\
$\square$ & $\mathrm{d}=1.4 \mathrm{~mm}$
\end{tabular}

Fig. 4 Normalised voltage difference $\left(\frac{\Delta \mathrm{V}_{\mathrm{t}-\mathrm{r} 1}\left(x_{0}\right)-\Delta \mathrm{V}_{\mathrm{t}-\mathrm{r} 2}\left(x_{0}\right)}{\mathrm{V}_{0}}\right)$ from $\mathrm{T}-\mathrm{R}_{1}$ and $\mathrm{T}-\mathrm{R}_{2}$ versus displacement along scanning direction $\left(x_{0}\right)$ for different crack depths (a) Real part (b) Imaginary part

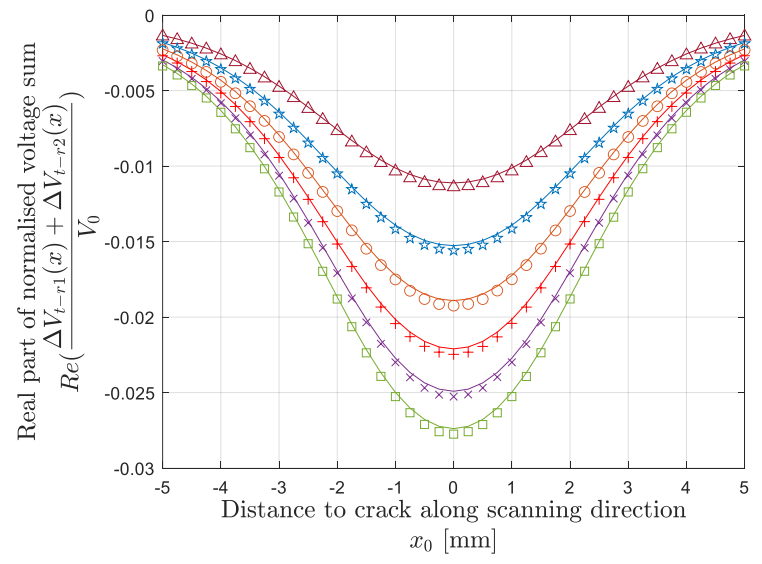

(a) (1)
Frequency, $\mathrm{f}=40 \mathrm{kHz}$ Skin depth, $\delta=0.12 \mathrm{~mm}$ Distance to crack along scanning direction, $x_{0}$

Crack depth, d Lines - analytical result Markers - experimental result Crack angle, $\varphi=45$ [degree]

$\begin{array}{rl}\triangle & \mathrm{d}=0.4 \mathrm{~mm} \\ \text { मे } & \mathrm{d}=0.6 \mathrm{~mm} \\ 0 & \mathrm{~d}=0.8 \mathrm{~mm} \\ + & \mathrm{d}=1 \mathrm{~mm} \\ \times & \mathrm{d}=1.2 \mathrm{~mm} \\ \square & \mathrm{d}=1.4 \mathrm{~mm}\end{array}$

Fig. 5 Normalised voltage change sum $\left(\frac{\Delta \mathrm{V}_{\mathrm{t}-\mathrm{r} 1}\left(x_{0}\right)+\Delta \mathrm{V}_{\mathrm{t}-\mathrm{r} 2}\left(x_{0}\right)}{\mathrm{V}_{0}}\right)$ versus displacement along scanning direction $\left(x_{0}\right)$ for different crack depths (a) Real part (b) Imaginary part

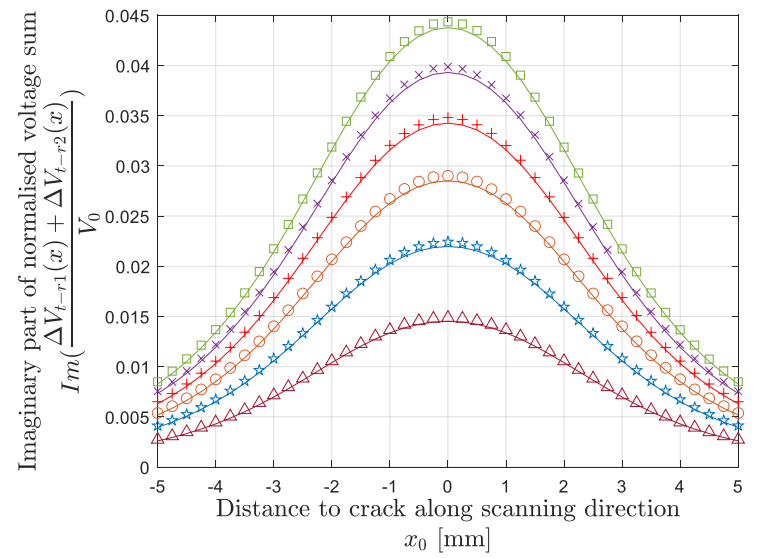

(b)
TABLE II

PARAMETERS OF THE FERROUS STEEL WITH LONG SURFACE SLOTS

\begin{tabular}{c|lc}
\hline \hline \multicolumn{2}{l}{ Parameter } & Value \\
\hline Ferrite-austenite & Electrical conductivity $\sigma(\mathrm{MS} / \mathrm{m})$ & 3.81 \\
steel alloy - & Relative permeability $\mu_{\mathrm{r}}$ & 122 \\
Dual-phase (DP) & Thickness $(\mathrm{mm})$ & 1.8 \\
1000 & Skin depth $\delta(\mathrm{mm})$ under $40 \mathrm{kHz}$ & 0.12 \\
\hline \multirow{4}{*}{ Machined surface } & Length $(\mathrm{mm})$ & 10.0 \\
slot & Width/gape w $(\mathrm{mm})$ & 0.25 \\
& Depth d $(\mathrm{mm})$ & $0.4: 0.2: 1.4$ \\
& Rotary angle $\varphi($ degree $)$ & $0: 5: 180$ \\
& Slots distance $(\mathrm{mm})$ & 50 \\
\hline
\end{tabular}

\section{RESULTS AND DISCUSSIONS}

Fig. 4 and Fig. 5 show the comparison of analytical (solid ines) and scanned results (markers) for the difference and sum of the normalised voltage change (from $T-R_{1}$ and $T-R_{2}$ sensing pairs) versus scanning displacement, respectively. The result is for the crack slot with the same angle of 45 degrees but different depths. It can be observed that the normalised voltage difference in Fig. 4 is centrosymmetric whereas the normalised oltage sum in Fig. 5 is $y-$ axially symmetric. Moreover, the

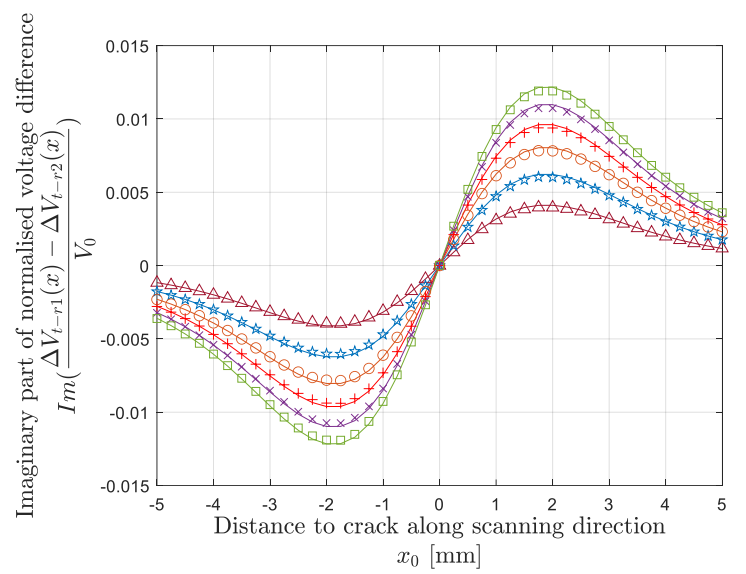

(b) 


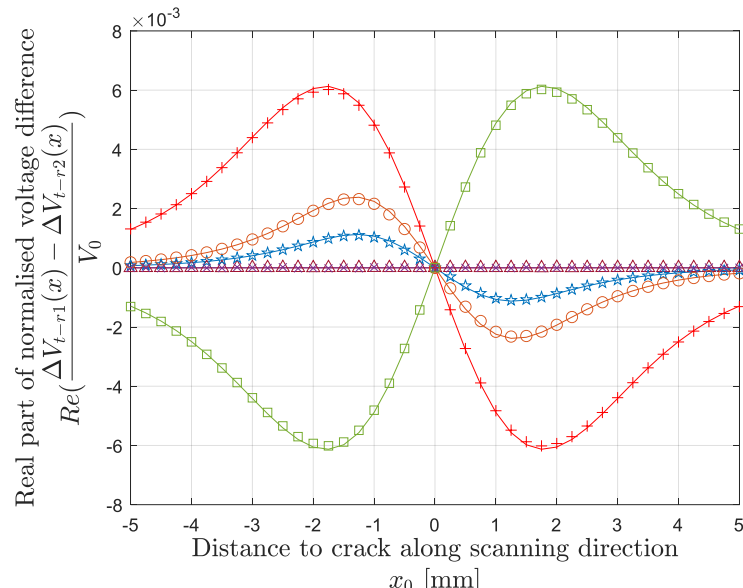

(a)

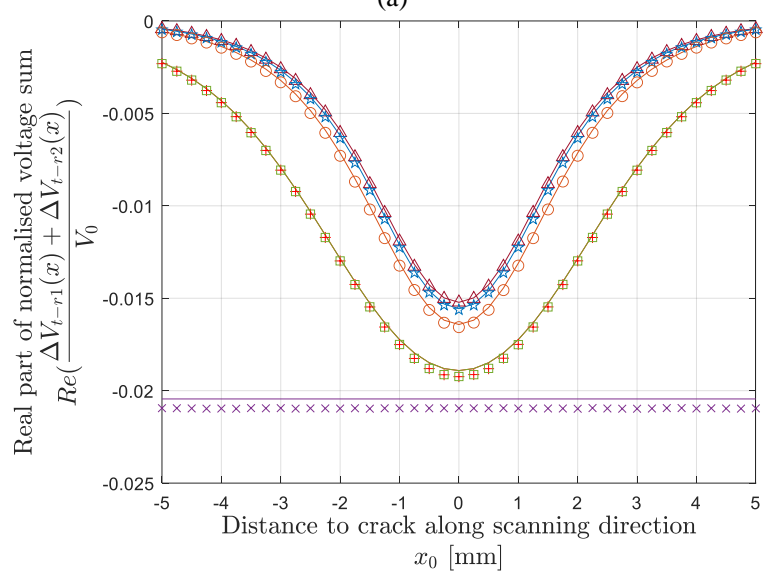

(c)
Frequency, $\mathrm{f}=40 \mathrm{kHz}$ Skin depth, $\delta=0.12 \mathrm{~mm}$ Distance to crack along scanning direction, $x_{0}$

Crack depth, $\mathrm{d}=0.8 \mathrm{~mm}$ Lines - analytical result Markers - experimental result Crack angle, $\varphi$

\begin{tabular}{|ll|}
\hline$\triangle$ & $\varphi=0$ [degree] \\
मt & $\varphi=10$ [degree] \\
0 & $\varphi=20$ [degree] \\
+ & $\varphi=45$ [degree] \\
$\times$ & $\varphi=90$ [degree] \\
$\square$ & $\varphi=135$ [degree] \\
\hline
\end{tabular}

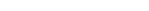

\section{Frequency, $\mathrm{f}=40 \mathrm{kHz}$ Skin depth, $\delta=0.12 \mathrm{~mm}$ Distance to crack along scanning direction, $x_{0}$ \\ Crack depth, $\mathrm{d}=0.8 \mathrm{~mm}$ Lines - analytical result Markers - experimental result Crack angle, $\varphi$

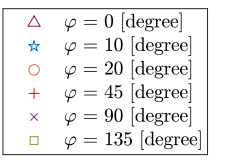

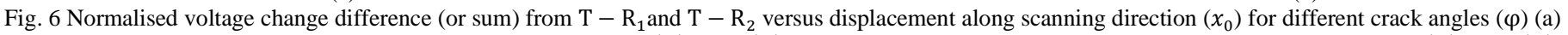

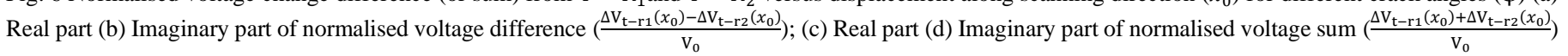

magnitude of both the sum and difference of the normalised voltage increases with the slot depth. For the case of the displacement $x_{0}=0 \mathrm{~mm}$ (the transmitter $\mathrm{T}$ is above the centre of the crack), two receivers are spatially centrosymmetric at the crack centre, which results in an identical signal from two receivers. Overall, both the real part and imaginary part of the analytical normalised voltage sum (or difference) fit that of the experimental result for a fixed crack angle of 45 degrees, with the error controlled within $3.0 \%$. The maximum percentage error occurs at the minimum crack depth $(0.4 \mathrm{~mm})$, which should substantially larger than the skin depth $(0.12$ under 40 $\mathrm{kHz}$ ) (considering the valid criterion of the EC thin-skin regime).

\section{B. Scanned voltage for different crack orientations}

Fig. 6 illustrates the comparison of analytical (solid lines) and experimental (markers) results for the difference and sum of the normalised voltage change (from $T-R_{1}$ and $T-R_{2}$ sensing pairs) versus scanning displacement for the crack slot with the same depth of $0.8 \mathrm{~mm}$ but different angles. Similar to the trend in Fig. 4 and Fig. 5, the normalised voltage (change) difference (in Fig. 6 a and b) and sum (in Fig. $6 \mathrm{c}$ and d) is centrosymmetric and $y-$ axially symmetric respectively. As the crack angle increases from 0 to 180 degrees, the real part (or imaginary part) of the normalised voltage difference gradually

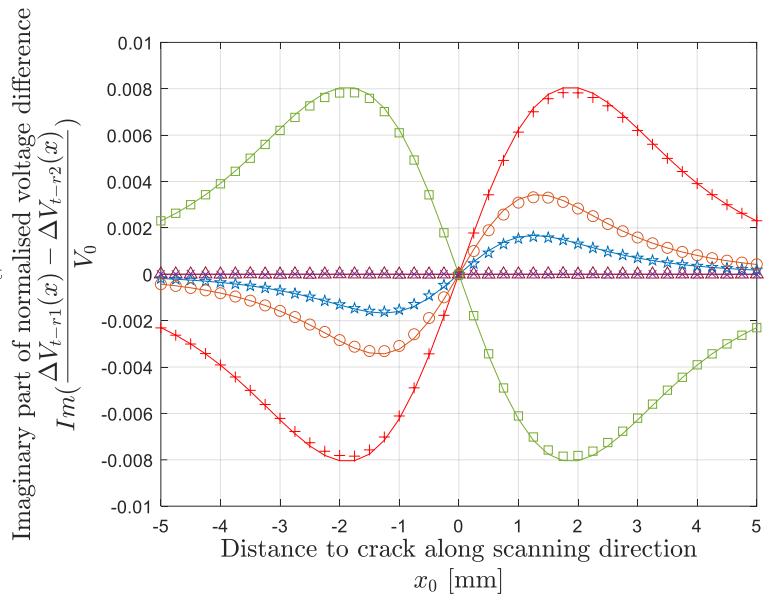

(b)

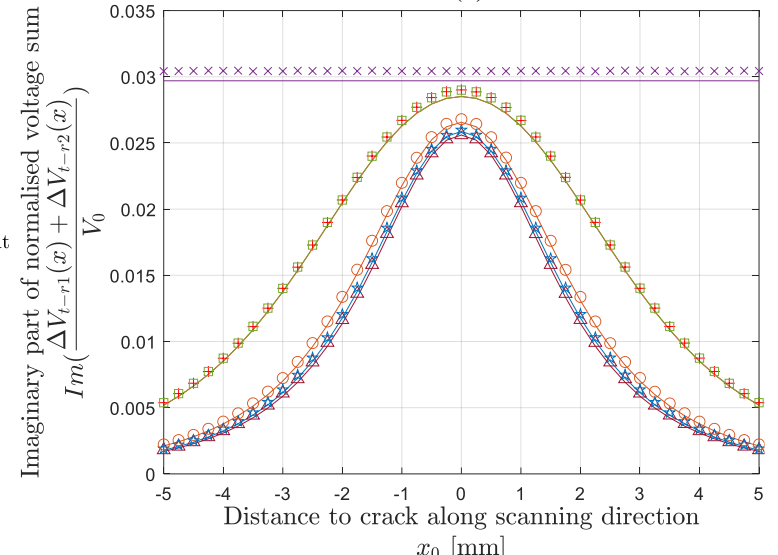
$x_{0}[\mathrm{~mm}]$

(d) changes from left-lobe (or right-lobe) positive to right-lobe (or left-lobe) positive. The discrepancy between the analytical and experimental result is caused by the approximation of the thinskin regime, the precision of the scanning system, the distance between the coil windings and crack (a larger distance could lead to a low Signal-to-noise ratio (SNR) due to the weakly coupled effect), and the impedance sensitivity to crack angles and depths. Considering the magnitude of both the normalised voltage sum and difference, the result at the displacement $x_{0}=$ $-1 \mathrm{~mm}$ is used for the further effect analysis of crack orientations.

\section{Voltage for different crack orientations}

Fig. 7 (a) exhibits the comparison of analytical (solid lines) and experimental (markers) results for the normalised voltage difference and sum (at the displacement $x_{0}=-1 \mathrm{~mm}$ ) versus crack angles with different crack depths. Similar to the trend in Fig. 4 and Fig. 5, an increased crack depth results in a larger signal magnitude (for both normalised voltage difference and sum). The discrepancy between the experimental and analytical reaches the peak value (less than $3.0 \%$ ) at the crack angle of 90 degrees, which is caused by the largest distance between the receiver and crack centre. Consequently, at the crack angle of 90 degrees, the sensor scans along with the crack orientation; and two receiver coil windings never skim over the surface 


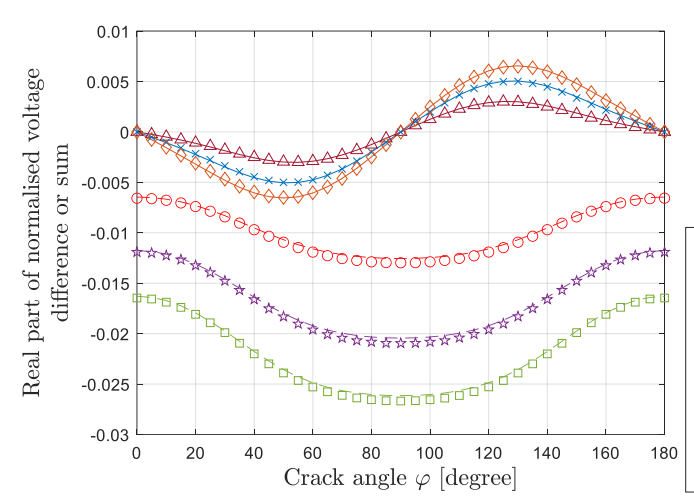

(a)

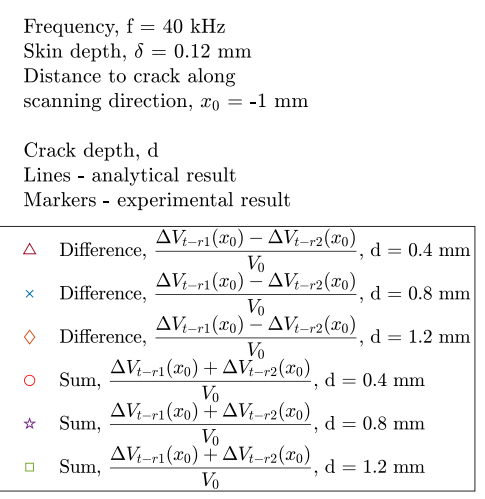

Skin depth, $\delta=0.12$

Distance to crack along

nning direction, $x_{0}=-1 \mathrm{~mm}$

Difference, $\frac{\Delta V_{t-r 1}\left(x_{0}\right)-\Delta V_{t-r 2}\left(x_{0}\right)}{\Delta V_{t}}, \mathrm{~d}=0.4 \mathrm{~mm}$

Difference, $\frac{\Delta V_{t-r 1}\left(x_{0}\right)-\Delta V_{t-r 2}\left(x_{0}\right)}{V_{0}}, \mathrm{~d}=0.8 \mathrm{~mm}$

Difference, $\frac{\Delta V_{t-r 1}\left(x_{0}\right)-\Delta V_{0}}{V_{t-r 2}\left(x_{0}\right)}, \mathrm{d}=1.2$
Sum, $\frac{\Delta V_{t-r 1}\left(x_{0}\right)+\Delta V_{t-22}\left(x_{0}\right)}{V}, \mathrm{~d}=0.4 \mathrm{~mm}$

Sum, $\frac{\Delta V_{t-r 1}\left(x_{0}\right)+\Delta V_{t-r 2}\left(x_{0}\right)}{V}, \mathrm{~d}=0.8 \mathrm{~mm}$

Sum, $\frac{\Delta V_{t-r 1}\left(x_{0}\right)+\Delta V_{t-r 2}\left(x_{0}\right)}{V_{0}}, \mathrm{~d}=1.2 \mathrm{~mm}$

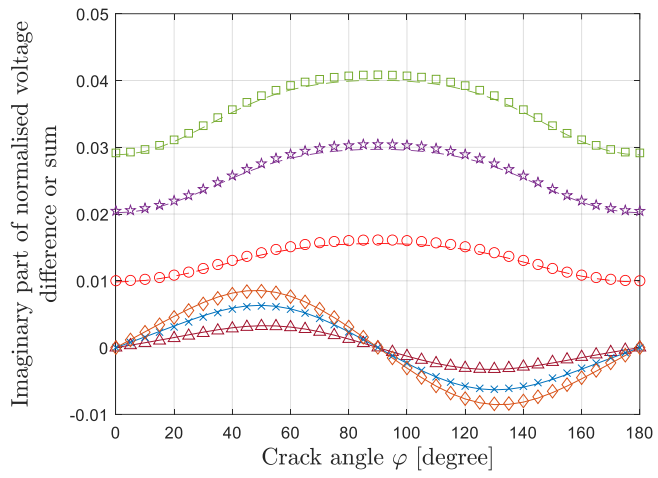

(b)

Fig. 7 (a) Real part (b) Imaginary part of normalised voltage change difference and sum $\left(\frac{\Delta \mathrm{V}_{\mathrm{t}-\mathrm{r} 1}\left(x_{0}\right)-\Delta \mathrm{V}_{\mathrm{t}-\mathrm{r} 2}\left(x_{0}\right)}{\mathrm{V}_{0}}\right.$ and $\left.\frac{\Delta \mathrm{V}_{\mathrm{t}-\mathrm{r} 1}\left(x_{0}\right)+\Delta \mathrm{V}_{\mathrm{t}-\mathrm{r} 2}\left(x_{0}\right)}{\mathrm{V}_{0}}\right)$ versus crack angle $(\varphi)$ for different crack depths

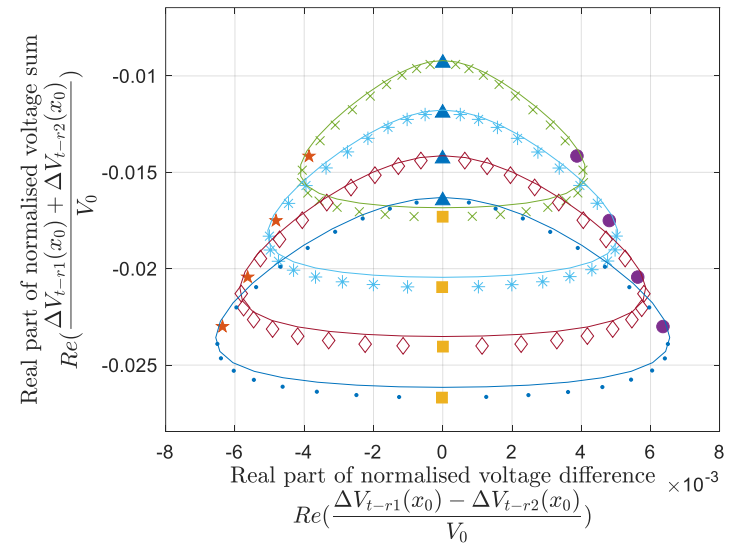

(a)

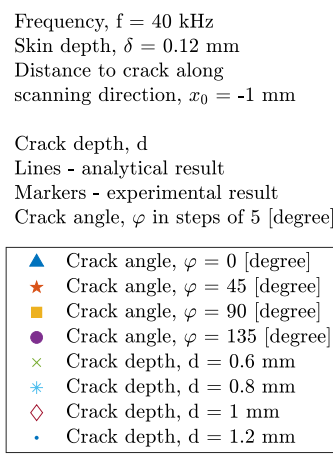

epth, $\delta=0.12 \mathrm{~mm}$

Distance to crack alon

Crack angle, $\varphi=0$ [degree]

Crack angle, $\varphi=45$ [degree]

Crack angle, $\varphi=90$ [degree] Crack depth, $\mathrm{d}=0.6 \mathrm{~mm}$

ck depth, $\mathrm{d}=0.8 \mathrm{~mm}$

Crack depth, $\mathrm{d}=1.2 \mathrm{~mm}$

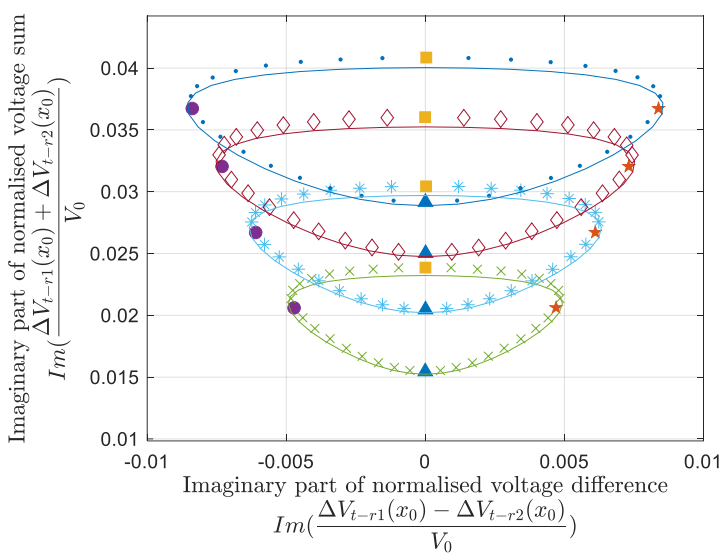

(b)

Fig. 8 (a) Real part (b) Imaginary part of diagram for normalised voltage change sum $\left(\frac{\Delta \mathrm{V}_{\mathrm{t}-\mathrm{r} 1}\left(x_{0}\right)+\Delta \mathrm{V}_{\mathrm{t}-\mathrm{r} 2}\left(x_{0}\right)}{\mathrm{V}_{0}}\right)$ versus difference $\left(\frac{\Delta \mathrm{V}_{\mathrm{t}-\mathrm{r} 1}\left(x_{0}\right)-\Delta \mathrm{V}_{\mathrm{t}-\mathrm{r} 2}\left(x_{0}\right)}{\mathrm{V}_{0}}\right)$ with different crack angles $(\varphi)$ and depths

crack.

In Fig. 7, the normalised voltage (change due to the crack) sum, $\frac{\Delta \mathrm{V}_{\mathrm{t}-\mathrm{r} 1}\left(x_{0}\right)+\Delta \mathrm{V}_{\mathrm{t}-\mathrm{r} 2}\left(x_{0}\right)}{\mathrm{V}_{0}}$ is monotonic to the crack angle $(\varphi)$ in the ranges from 0 to 90 degrees and from 90 to 180 degrees. Therefore, the crack angle can be retrieved from both ranges $\left(0^{\circ} \sim 90^{\circ}\right.$ and $\left.90^{\circ} \sim 180^{\circ}\right)$, but not the whole angle domain $\left(0^{\circ} \sim 180^{\circ}\right)$. Thus, an additional feature is required for judging which range $\left(0^{\circ} \sim 90^{\circ}\right.$ or $\left.90^{\circ} \sim 180^{\circ}\right)$ the crack angle distributes in. It can be found in Fig. 7 (a) and (b) that the normalised voltage difference $\left(\frac{\Delta \mathrm{V}_{\mathrm{t}-\mathrm{r} 1}\left(x_{0}\right)-\Delta \mathrm{V}_{\mathrm{t}-\mathrm{r} 2}\left(x_{0}\right)}{\mathrm{V}_{0}}\right)$ is centrosymmetric at $\varphi=90^{\circ}$. Therefore, the crack angle can be retrieved by combining both the normalised voltage sum and difference.

\section{Retrieval of surface crack orientation}

Fig. 8 depicts the comparison of analytical (solid lines) and experimental (markers) diagram for the normalised voltage (change due to the crack) $\operatorname{sum}\left(\frac{\Delta \mathrm{V}_{\mathrm{t}-\mathrm{r} 1}\left(x_{0}\right)+\Delta \mathrm{V}_{\mathrm{t}-\mathrm{r} 2}\left(x_{0}\right)}{\mathrm{V}_{0}}\right)$ versus difference $\left(\frac{\Delta \mathrm{V}_{\mathrm{t}-\mathrm{r} 1}\left(x_{0}\right)-\Delta \mathrm{V}_{\mathrm{t}-\mathrm{r} 2}\left(x_{0}\right)}{\mathrm{V}_{0}}\right)$ with different crack depths and orientations. As shown in the legend of Fig. 8, 4 different markers are used to label different millstones of crack angles $\left(0^{\circ}, 45^{\circ}, 90^{\circ}, 135^{\circ}\right)$. The experimental result fits the analytical one, with the maximum discrepancy occurs at $90^{\circ}$. The crack angle can be retrieved by referring to both the real and

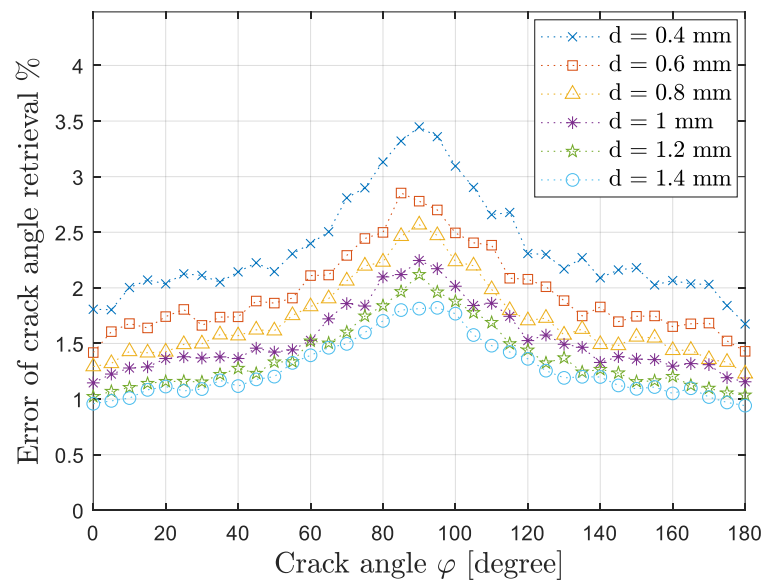

Fig. 9 Error of retrieved crack angle versus actual value for different crack depths

imaginary parts of the voltage diagram.

Referring to either the real part in Fig. 8 (a) or the imaginary part in Fig. 8 (b), the angle of the surface crack is retrieved. Since the inductance change dominates under high frequencies (compared to the resistance) [14,46-48], the imaginary part in Fig. 8 (b) is used for the orientation retrieval. As shown in Fig. 9, for each crack orientation, the error of the retrieved crack angle decreases with crack depth, which is expected from the criterion of the EC thin-skin regime. For each crack depth, owing to the maximum discrepancy at 90 degrees (as discussed in section $\mathrm{C}$ ), the error of the retrieved crack angle peaks at $\varphi=$ 
$90^{\circ}$. Overall, the error of the crack orientation retrieval can be controlled within $3.5 \%$. As the curves of different depth intersect, the depth of surface defect is set as a prior for the proposed method, which can be evaluated by rotating field eddy-current techniques $[34,35]$.

\section{CONCLUSION}

Based on the EC thin-skin regime, a revised analytical algorithm is proposed for the mutual impedance of the driverpickup coil winding scanning over long surface crack slots with different angles. For the retrieval of crack orientation, instead of spatially rotating a single driver-pickup coil winding, an additional sensing coil is included in the designed triple-coil driver-pickup EC sensor. Considering the reversibility of the signal-angle function, a monotonic behaviour is found between the normalised voltage diagram and crack angles. Results show that by referring to the voltage diagram of the normalised voltage difference versus sum, the error of the crack orientation retrieval is controlled within $3.5 \%$ for different crack depths. In the practical measurement, both the length, depth, and orientation of surface defects affect eddy-current signals. The length and depth of surface defects can be determined or classified by other techniques including the ACFM [32,33] (for defect length retrieval), and rotating-field eddy current sensor $[34,35]$ (for defect depth retrieval). The proposed method aims to incorporate those existing techniques for the further determination of crack orientations. Therefore, high-frequency signals are commonly used so that a relatively thin skin depth satisfies.

Besides, to ensure that the proposed method is less affected by the border of the defect (when the sensor pass near the defect border), it is suggested to use sensor arrays (particularly in a line and perpendicular to the scanning direction) with relatively small coil diameter to inspect surface crack. The defect orientation is retrieved from the sensor with the most significant voltage change (among arrays) when using the proposed method (based on eddy-current thin-skin regime). Moreover, the scanning position of $x_{0}=-1 \mathrm{~mm}$ can be identified from sensor arrays (along scanning direction) with a spacing of $1 \mathrm{~mm}$ by comparing their signals.

The defect clusters are commonly located using the ultrasonic sensor. Besides, eddy current sensors are used to incorporate with ultrasonic sensors to quantity the dimension of defects. Due to the skin effect, where the eddy current is confined near the surface of test piece, the eddy current testing only applies to surface or near-surface defects. Moreover, the defect may be irregular (asymmetric) in practical measurement (particularly for small defect compared to the sensor diameter). Further investigations on the inspections of sub-surface defects and even asymmetric defects will be carried out in the future.

\section{ACKNOWLEDGEMENT}

Author Contributions: (Methodology, manuscript drafting) M. Lu and X. Meng; (conceptualization, revision) M. Lu; (experiment data curation, apparatus fabrication) M. Lu, X. Meng, R. Huang, L. Chen, Z. Tang, J. Li; (administration) M. Lu, W. Yin, A. Peyton. All authors have read and agreed to the published version of the manuscript.

\section{APPENDIX}

Followings show the definition of parameters $g(w), k$, and $\widetilde{\mathrm{U}}$ in equation (2),

$$
g(w)=j g_{\mathrm{f}} \mathrm{w}+(1+\mathrm{j}) \mu_{\mathrm{r}} \delta\left(\mathrm{g}_{\mathrm{f}}-\frac{\mathrm{g}_{\mathrm{s}} \mathrm{w}}{2}\right)+\frac{\mathrm{g}_{\mathrm{k}} \mu_{\mathrm{r}} \delta^{2}}{2}
$$

In (1),

$$
\begin{gathered}
\mathrm{g}_{\mathrm{f}}=v \tanh (v \mathrm{~d}) \\
\mathrm{g}_{\mathrm{s}}=\left[1+\frac{2 v}{\mathrm{jk}}(\widetilde{\mathrm{U}}+\widetilde{\mathrm{V}}) \tanh (v \mathrm{~d})-\operatorname{sech}(v \mathrm{~d})\right] v^{2} \\
\mathrm{~g}_{\mathrm{k}}=\left\{\operatorname{sech}(v \mathrm{~d})-\frac{8}{\pi}\left[1+\frac{v}{\mathrm{jk}}(\widetilde{\mathrm{U}}+\widetilde{\mathrm{V}}) \tanh (v \mathrm{~d})-\operatorname{sech}(v \mathrm{~d})\right]\right\} v^{2} \\
\mathrm{In}(4), \widetilde{\mathrm{U}} \text { and } \widetilde{\mathrm{V}} \text { are even functions and defined as, } \\
=\frac{\mu_{\mathrm{r}}}{2 \pi\left[\left(\mu_{\mathrm{r}}^{2}-1\right) \varepsilon^{2}+\mu_{\mathrm{r}}^{2}\right]}\left[\frac{\mu_{\mathrm{r}}}{\varepsilon} \ln \left(\frac{1+\varepsilon}{1-\varepsilon}\right)-\frac{1}{\sqrt{1+\varepsilon^{2}}} \ln \left(\frac{1+\sqrt{1+\varepsilon^{2}}}{1-\sqrt{1+\varepsilon^{2}}}\right)\right. \\
\left.+\frac{\mu_{\mathrm{r}}^{2}-1}{\sqrt{\left(\mu_{\mathrm{r}}^{2}-1\right) \varepsilon^{2}+1}} \ln \left(\frac{\sqrt{\left(\mu_{\mathrm{r}}^{2}-1\right) \varepsilon^{2}+1}+\mu_{\mathrm{r}} \sqrt{\left(\mu_{\mathrm{r}}^{2}-1\right) \varepsilon^{2}+1}-1}{\sqrt{\left(\mu_{\mathrm{r}}^{2}-1\right) \varepsilon^{2}+1}-\mu_{\mathrm{r}}} \frac{\mu_{\mathrm{r}}}{\sqrt{\left(\mu_{\mathrm{r}}^{2}-1\right) \varepsilon^{2}+1}+1}\right)\right] \\
\widetilde{\mathrm{V}}=-\frac{\operatorname{li}^{2 \pi \sqrt{\left(\mu_{\mathrm{r}}^{2}-1\right) \varepsilon^{2}+1}}}{\times \ln \left(\frac{\sqrt{\left(\mu_{\mathrm{r}}^{2}-1\right) \varepsilon^{2}+1}+\mu_{\mathrm{r}}}{\sqrt{\left(\mu_{\mathrm{r}}^{2}-1\right) \varepsilon^{2}+1}-\mu_{\mathrm{r}}} \frac{\sqrt{\left(\mu_{\mathrm{r}}^{2}-1\right) \varepsilon^{2}+1}-1}{\sqrt{\left(\mu_{\mathrm{r}}^{2}-1\right) \varepsilon^{2}+1}+1}\right)}
\end{gathered}
$$

For the non-magnetic materials, $\widetilde{U}$ and $\widetilde{V}$ are defined as,

$$
\begin{gathered}
\widetilde{U}=\frac{1}{2 \pi}\left[\frac{1}{\varepsilon} \ln \left(\frac{1+\varepsilon}{1-\varepsilon}\right)-\frac{1}{\sqrt{1+\varepsilon^{2}}} \ln \left(\frac{1+\sqrt{1+\varepsilon^{2}}}{1-\sqrt{1+\varepsilon^{2}}}\right)\right] \\
\widetilde{V}=-\frac{1}{\pi} \ln \left(\frac{\varepsilon}{\sqrt{\varepsilon^{2}-1}}\right)
\end{gathered}
$$

In (4), $\mathrm{k}$ is defined as,

$$
\mathrm{k}=\frac{-1+\mathrm{j}}{\delta}
$$

In (5), (6), (7), and (8),

$$
\varepsilon=\frac{v}{\mathrm{k}}
$$

\section{REFERENCES}

[1] D. Vasic, V. Bilas, and D. Ambrus, "Pulsed eddy-current nondestructive testing of ferromagnetic tubes," IEEE Transactions on Instrumentation and Measurement, vol. 53, no. 4, pp. 1289-1294, Aug. 2004.

[2] J. R. Gallion, and R. Zoughi. "Millimeter-wave imaging of surfacebreaking cracks in steel with severe surface corrosion." IEEE Transactions on Instrumentation and Measurement 66, no. 10, pp. 27892791, 2017.

[3] M. S. Luloff, J. Morelli, and T. W. Krause, "Examination of Dodd and Deeds solutions for a transmit-receive eddy current probe above a layered planar structure," AIP Conference Proceedings. AIP Publishing LLC, vol. 1806, no. 1, 2017.

[4] G.Y. Tian, and A. Sophian, "Defect classification using a new feature for pulsed eddy current sensors," Ndt \& E International, vol. 38, no. 1, pp. 77-82, 2005.

[5] M. Lu, L. Yin, A. J. Peyton, and W. Yin, "A novel compensation algorithm for thickness measurement immune to lift-off variations using eddy current method," IEEE Transactions on Instrumentation and Measurement, vol. 65, no. 12, pp. 2773-2779, Dec. 2016.

[6] M. Lu et al., "Thickness measurement of metallic film based on a highfrequency feature of triple-coil electromagnetic eddy current sensor," IEEE Transactions on Instrumentation and Measurement, early access, 2020. DOI: 10.1109/TIM.2020.3027929.

[7] A. V. Egorov, V. V. Polyakov, D. S. Salita, E. A. Kolubaev, S. G. Psakhie, A. G. Chernyavskii, I. V. Vorobei, "Inspection of aluminum alloys by a multi-frequency eddy current method," Defence Technology, vol. 11, no. 2, pp. 99-103, 2015.

[8] M. Lu, X. Meng, W. Yin, Z. Qu, F. Wu, J. Tang, et al., "Thickness measurement of non-magnetic steel plates using a novel planar triple-coil sensor,” NDT \& E International, vol. 107, 2019. 
[9] J.R.S. Avila et al., "Accurate measurements of plate thickness with variable lift-off using a combined inductive and capacitive sensor," NDT \& E International, vol. 110, pp. 102202, 2020.

[10] R. Huang et al., "Thickness measurement of metallic plates with finite planar dimension using eddy current method," IEEE Transactions on Instrumentation and Measurement, vol. 69, pp. 8424-8431, 2020.

[11] M. Lu, H. Xu, W. Zhu, and L. Yin et al., "Conductivity Lift-off Invariance and measurement of permeability for ferrite metallic plates," NDT \& E International, vol. 95, pp. 36-44, Apr. 2018.

[12] M. Lu, R. Huang, W. Yin, Q. Zhao, and A. Peyton, "Measurement of permeability for ferrous metallic plates using a novel lift-off compensation technique on phase signature," IEEE Sensors Journal, vol. 19, no. 17, pp. 7440-7446, 1 Sept.1, 2019.

[13] M. Lu et al., "Measurement of ferromagnetic slabs permeability based on a novel planar triple-coil sensor," IEEE Sensors Journal, vol. 20, no. 6, pp. 2904-2910, 2020.

[14] M. Lu, W. Zhu, L. Yin, A. J. Peyton, W. Yin, and Z. Qu, "Reducing the lift-off effect on permeability measurement for magnetic plates from multifrequency induction data," IEEE Transactions on Instrumentation and Measurement, vol. 67, no. 1, pp. 167-174, Jan. 2018.

[15] M. Lu et al., "Determination of the magnetic permeability, electrical conductivity, and thickness of ferrite metallic plates using a multifrequency electromagnetic sensing system," IEEE Transactions on Industrial Informatics, vol. 15, pp. 4111-4119, 2019.

[16] M. Lu et al., "Measuring lift-off distance and electromagnetic property of metal using dual-frequency linearity feature," IEEE Transactions on Instrumentation and Measurement, early access, 2020. DOI: 10.1109/TIM.2020.3029348.

[17] W. Yin et al., "An equivalent-effect phenomenon in eddy current nondestructive testing of thin structures," IEEE Access, vol. 7, pp. 7029670307, 2019.

[18] R. Hamia, C. Cordier, and C. Dolabdjian, "Eddy-current non-destructive testing system for the determination of crack orientation," NDT \& E International, vol. 61, pp. 24-28, 2014.

[19] A. Joshi, L. Udpa, S. Udpa, and A. Tamburrino, "Adaptive wavelets for characterizing magnetic flux leakage signals from pipeline inspection," IEEE transactions on magnetics, vol. 42, no. 10, pp. 3168-3170, 2006.

[20] R. C. Ireland, and C. R. Torres, "Limitations of the circumferential MFL technique in the NDE of pipelines," Proceedings of magnetics on nondestructive testing Seminar. London, UK, 2005.

[21] J. R. Bowler, S. J. Norton, and D. J. Harrison, "Eddy-current interaction with an ideal crack. II. The inverse problem," Journal of applied physics, VOL. 75, no. 12, PP. 8138-8144, 1994.

[22] S. K. Burke, "Eddy-current inversion in the thin-skin limit: Determination of depth and opening for a long crack," Journal of applied physics, vol. 76, no. 5, pp. 3072-3080, 1994.

[23] L. Yin et al., "Detection of corrosion pits based on an analytically optimised eddy current sensor," Insight-Non-Destructive Testing and Condition Monitoring, vol. 60, no. 10, pp. 561-567, 2018.

[24] G. Betta, L. Ferrigno, and M. Laracca, "GMR-based ECT instrument for detection and characterization of crack on a planar specimen: A hand-held solution," IEEE transactions on instrumentation and measurement, vol. 61, no. 2, pp. 505-512, 2011.

[25] Z. Zeng, L. Udpa, S. S. Udpa, and M. S. C. Chan, "Reduced magnetic vector potential formulation in the finite element analysis of eddy current nondestructive testing," IEEE transactions on magnetics, vol. 45, no. 3 pp. 964-967, 2009.

[26] N. Harfield, and J. R. Bowler, "Theory of thin-skin eddy-current interaction with surface cracks," Journal of applied physics, vol. 82, no. 9, pp. 4590-4603, 1997.

[27] B. A. Auld, and J. C. Moulder, "Review of advances in quantitative eddy current nondestructive evaluation," Journal of Nondestructive evaluation 18, no. 1, pp. 3-36, 1999.

[28] S. K. Burke, and R. J. Ditchburn, "Mutual impedance of planar eddycurrent driver-pickup spiral coils," Research in Nondestructive Evaluation 19, no. 1, pp. 1-19, 2008.

[29] T. Theodoulidis, "Analytical model for tilted coils in eddy-current nondestructive inspection," IEEE transactions on magnetics, vol. 41, no. 9, pp. 2447-2454, 2005.

[30] O. Bíró, "Edge element formulations of eddy current problems," Comput. Methods Appl. Mech. Eng., vol. 169, nos. 3-4, pp. 391-405, 1999.
[31] T. Theodoulidis, N. Poulakis, and A. Dragogias, "Rapid computation of eddy current signals from narrow cracks," NDT \& E International, vol. 43, no. 1, pp. 13-19, 2010.

[32] G. L. Nicholson, and C. L. Davis, "Modelling of the response of an ACFM sensor to rail and rail wheel RCF cracks," NDT \& E International, vol. 46, pp. 107-114, 2012.

[33] M. P. Papaelias, M. C. Lugg, C. Roberts, and C. L. Davis, "High-speed inspection of rails using ACFM techniques," NDT\&E International, vol. 42, no. 4, pp. 328-335, 2009.

[34] G. Yang, G. Dib, L. Udpa, A. Tamburrino and S. S. Udpa, "Rotating Field EC-GMR Sensor for Crack Detection at Fastener Site in Layered Structures," IEEE Sensors Journal, vol. 15, no. 1, pp. 463-470, Jan. 2015.

[35] W. Li, X. Yuan, G. Chen, J. Ge, X. Yin and K. Li, "High sensitivity rotating alternating current field measurement for arbitrary-angle underwater cracks," NDT \& E International, vol. 79, pp. 123-131, Apr. 2016.

[36] M. Lu et al., "Acceleration of frequency sweeping in eddy-current computation," IEEE Transactions on Magnetics, vol. 53, pp. 1-8, 2017.

[37] W. Yin, M. Lu et al., "Acceleration of eddy current computation for scanning probes," Insight-Non-Destructive Testing and Condition Monitoring, vol. 60, no. 10, pp. 547-555, 2018.

[38] R. Huang, M. Lu, A. Peyton, and W. Yin, "A novel perturbed matrix inversion based method for the acceleration of finite element analysis in crack-scanning eddy current NDT," IEEE Access, vol. 8, pp. 12438$12444,2020$.

[39] T. P. Theodoulidis, S. M. Panas, and E. E. Kriezis, "Eddy current detection of crack orientation using elliptical excitation," IEE Proceedings-Science, Measurement and Technology, vol. 141, no. 1, pp. 41-47, 1994.

[40] C. Dolabdjian, G. Wach, and L. Perez, "Improvement in the detection of subsurface fatigue cracks under airframe fasteners using improved rotating giant magneto-resistance magnetometer head," Insight-NonDestructive Testing and Condition Monitoring, vol. 49, no. 3, pp. 133136, 2007.

[41] Y. P. Ma, and J. P. Wikswo, "SQUID magnetometers for depth-selective, oriented eddy current imaging," In Review of Progress in Quantitative Nondestructive Evaluation, pp. 1067-1074. Springer, Boston, MA, 1998.

[42] J. Cheng et al., "Application of low frequency ECT method in noncontact detection and visualization of CFRP material," Composites Part B: Engineering, vol. 110, pp. 141-52, 2017.

[43] B. Cao et al., "Analytical model of tilted driver-pickup coils for eddy current nondestructive evaluation," Chin. Phys. B, vol. 27, pp. 030301. 2018.

[44] J. R. S. Avila, Z. Chen, H. Xu, and W. Yin, "A multi-frequency NDT system for imaging and detection of cracks," 2018 IEEE International Symposium on Circuits and Systems (ISCAS), pp. 1-4. IEEE, 2018.

[45] $\mathrm{H}$. Xu et al., "Imaging a weld cross-section using a novel frequency feature in multi-frequency eddy current testing," Insight-NonDestructive Testing and Condition Monitoring, vol. 61, no. 12, pp. 738743, 2019.

[46] X. Meng et al., " Inversion of lift-off distance and thickness for nonmagnetic metal using eddy current testing," IEEE Transactions on Instrumentation and Measurement, early access, 2020. DOI: 10.1109/TIM.2020.3038289.

[47] M. Lu et al., "Inversion of Distance and Magnetic Permeability Based on Material-Independent and Lift-off Insensitive Algorithms Using Eddy Current Sensor," IEEE Transactions on Instrumentation and Measurement, early access, 2020. DOI: 10.1109/TIM.2020.3036099.

[48] M. Lu et al., "Lift-off tolerant pancake eddy-current sensor for the thickness and spacing measurement of non-magnetic plates," IEEE Transactions on Instrumentation and Measurement, early access, 2020. DOI: 10.1109/TIM.2020.3033377.

[49] R. Huang et al., "Measuring Co-Axial Hole Size of Finite-Size Metallic Disk Based on a Dual-Constraint Integration Feature Using MultiFrequency Eddy Current Testing," IEEE Transactions on Instrumentation and Measurement, early access, 2020. DOI: 10.1109/TIM.2020.3026762

[50] R. Huang et al., "Measurement of the radius of metallic plates based on a novel finite region eigenfunction expansion (FREE) method," IEEE Sensors Journal, early access, 2020. DOI: 10.1109/JSEN.2020.3009443

[51] J. Tang et al., "A Novel Efficient FEM Thin Shell Model for BioImpedance Analysis," Biosensors, vol. 10, no. 6, pp. 69, 2020. 
[52] L. Chen, et al., "Textile Based Capacitive Sensor for Physical Rehabilitation via Surface Topological Modification," ACS Nano, vol. 14, no. 7, pp. 8191-8201, 2020. DOI: 10.1021/acsnano.0c01643

[53] Z. Jin, et al., "Methods of Controlling Lift-off in Conductivity Invariance Phenomenon for Eddy Current Testing," IEEE ACCESS, vol. 8, pp. 2169-3536, 2020. DOI: 10.1109/ACCESS.2020.3007216.

[54] J. Tang, et al., "Effect of frozen-thaw injury on cell membrane and bioimpedance," In 2020 IEEE International Instrumentation and Measurement Technology Conference (I2MTC), pp. 1-6. IEEE, 2020.

[55] J. Tang, et al., "Bio-impedance spectroscopy for frozen-thaw of biosamples: Non-contact inductive measurement and finite element (FE) based cell modelling," Journal of Food Engineering, vol. 272, pp. 109784, 2020.

[56] H. Xu et al., "Imaging a weld cross-section using a novel frequency feature in multi-frequency eddy current testing," Insight-NonDestructive Testing and Condition Monitoring, vol. 61, no. 12, pp. 738 743, 2019.

[57] Y. Xie et al., "Novel Wearable Sensors for Biomechanical Movement Monitoring Based on Electromagnetic Sensing Techniques," IEEE Sensors Journal, vol. 20, no. 2, 2020. DOI: 10.1109/JSEN.2019.2943487

[58] W. Yin et al., "Permeability invariance phenomenon and measurement of electrical conductivity for ferrite metallic plates," Insight-NonDestructive Testing and Condition Monitoring, vol. 61, no. 8, pp. 472 479, 2019.

[59] M. Lu et al., "A model for the triboelectric nanogenerator with inductive load and its energy boost potential," Nano Energy, vol. 63, pp. 103883, 2019.

[60] M. Lu et al., "Forward solver for deep earth exploration and induction logging using custom built Edge - Element FEM technique," Acta Geologica Sinica, vol. 93, pp. 302-304, 2019.

[61] L. Chen et al., "Whole System Design of Wearable Magnetic Induction Sensor for Physical Rehabilitation," Advanced Intelligent Systems, vol. 1, no. 1, pp. 1900037, 2019.

[62] Y. X et al., "A self-powered radio frequency (RF) transmission system based on the combination of triboelectric nanogenerator (TENG) and piezoelectric element for disaster rescue/relief," Nano Energy, vol. 54, pp. 331-340, 2018.

[63] W. Yin et al., "Custom edge-element FEM solver and its application to eddy-current simulation of realistic $2 \mathrm{M}$-element human brain phantom," Bioelectromagnetics, vol. 39, no. 8, pp. 604-616, 2018.

[64] L. Yin et al., "Detection of corrosion pits based on an analytically optimised eddy current sensor," Insight-Non-Destructive Testing and Condition Monitoring, vol. 60, no. 10, pp. 561-567, 2018.

[65] W. Yin et al., "Acceleration of eddy current computation for scanning probes," Insight-Non-Destructive Testing and Condition Monitoring, vol. 60, no. 10, pp. 547-555, 2018.

[66] W. Zhou et al., "Three-dimensional electromagnetic mixing models for dual-phase steel microstructures," Applied Sciences, vol. 8, no. 4, pp. 547-555, 2018.

[67] M. Lu, et al., "Determining the magnetic permeability of ferrite steel strip by a custom inversion method," In Proc. 12th ECNDT, pp. 1-8. 2018.

[68] J. Tang, et al., "Cellular structure analysis based on magnetic induction finite element method simulations and measurements," bioRxiv, pp. 275271, 2018. DOI: 10.1101/275271

[69] J.R.S. Avila, et al., "A novel dual modality sensor with sensitivities to permittivity, conductivity, and permeability," IEEE Sensors Journal, vol. 18, no. 1, pp. 356-362, 2017.

[70] T. Yang, et al., "Level measurement for saline with a small surface area using high frequency electromagnetic sensing technique," Measurement, vol. 101, pp. 118-125, 2017.

[71] M. Lu, et al., "Prediction of the asymptotical magnetic polarization tensors for cylindrical samples using the boundary element method," In 2015 IEEE Sensors Applications Symposium (SAS), pp. 1-4. IEEE, 2015.

[72] W. Yin, et al., "Measurements of thickness for metallic plates with coaxial holes using a novel analytical method with the modified integration range," IEEE Transactions on Instrumentation and Measurement, 2020. DOI: 10.1109/ACCESS.2020.3035333 